\title{
At the intersection of ambition, realism and capability allows for strategy to be successful in a digital era
}

\author{
Zuben Rustomjee \\ zrustomjee@au1.ibm.com | IBM, Level 28/60 City Rd, Southbank, VIC 3006, Australia \\ Letter From Industry
}

\begin{abstract}
With an ever-changing market environment, converging industries are constantly trying to compete innovatively using commercial and scientific acumen to create advantage. Previously, successful strategy employed a set of robust steps which now need to change so that these firms can ensure their ability to be competitive. In this day and age, strategy now involves balancing a desired end goal, a recognition of the actual skills and having digital lens to overlay any and all recommendations. Using technology as an enabler, firms can ensure that its goals and its people are in the best possible position to deliver.
\end{abstract}

Keywords. Reinvention; Change; Transformation; Technology; Strategy.

Cite paper as: Rustomjee, Z., (2018). At the intersection of ambition, realism and capability allows for strategy to be successful in a digital era - Letter From Industry, Journal of Innovation Management, www.open-jim.org, 6(1), 5-12. http://hdl.handle.net/10216/111571 


\section{Introduction}

Multinational corporations, governments, individuals and start-ups alike are now in a position where, to succeed, a revaluation of their current position is imperative to allow them to work towards incorporating a deeper aspect of digital into their business. To capitalise on the opportunities the new digital era brings, mitigating any impending social \& financial risks, companies and teams need to change their behaviours to ensure they can adapt at speed. Where we are seeing this now is through the level of real-time connectivity which enables everyone to engage world leaders, policy makers, entire businesses, friends and family making access to those channels all the more important to influence.

"The last best experience that anyone has anywhere, becomes the minimum expectation for the experience they want everywhere"

Referring to any experience a customer would go through (commonly referred to as "customer service'), the phrase, coined by Bridget van Kranlingen, the then, Senior Vice President of IBM's Global Business Services still rings true (Gowers, 2016). This phrase should always be present in the mind of every level of a legacy organisation or those trying to reengineer a new product or service from a café table, the question that keeps getting asked is:

\section{How can we add value to our customers?}

Although this question has always existed, as the ways that consumers and producers interact has evolved, so has consumer expectations. With changing social norms, in the palm of our hand is access to entire networks of friends and family, the ability to report on issues live and even to manage entire portfolios, giving everyone a level of control and influence, which was not previously there. This power of the consumer, where "the customer is always right" has again become reality for all industries whereby, word of mouth can now influence hundreds of people in an instant (IBM Business Analytics, 2013).

As such, companies are held to a new level of accountability whereby, their response time to issues and their overall responsibility are now very top of mind concerns which always need to be considered. Although companies recognise this need for continuous improvement, there still exists questions around the "what" and "how" but, many are failing to even adapt fast enough to avoid being consumed and forgotten during this disruption (Rishi, 2017).

\section{The changing paradigm of Strategy}

When we recollect how companies would traditionally address problems affecting their present and future position, working towards creating new 'strategy' would be the first step. These could take the form of a multi-year roadmap; sets of goals to ensure competitive advantage; quick win objectives for immediate cost reductions or; overhauling an operating model to promote talent $\&$ innovation. Although that list is far from comprehensive, it gives an idea into some of the outcomes of a strategic discussion where, regardless of which is chosen, the approach taken are all based on a structured methodology (Gavetti \& Rivkin 2005). These steps allow for strategists 
to make educated assumptions, document potential yet thorough outcomes and ultimately guide its recipients on the best possible path to success. Simply put, having a strong grasp of these steps can end month long boardroom debates in five minutes by having an attentive audience and a whiteboard.

This methodology can be broken down into four key steps:

1. External \& Internal Diagnosis: used to understand the current environment, any industrybased trends or behaviours. This research also analyses the current capabilities of the organisation that needs to perform the change.

2. Defining, Hypothesising \& Evaluating: all potential paths to success, considering those both realistic and ambitious. By modelling scenarios and balancing both risks \& returns from pursuing each option.

3. Determining the best course of action: by bringing together all key decision makers, proposing each option and finally selecting how to proceed. Based on trusting that all reasonably available facts are presented a decision can be made by leadership on the direction of the firm.

4. Streamlining the Decisions: to ensure the organisation and its people know that they have the support by decision makers, have leaders near the staff who can motivate change and finally that the staff on the ground can operate at the required level to achieve it desired goal $/ \mathrm{s}$.

Until recently, this was how the most ambiguous and imminent strategic problems were solved successfully however, this structured approach will also need to evolve to keep up with the constant industrial changes driven by digital disruption (Berman and Dalzell-Payne, 2017).

In a world where cognitive, technology and innovation nomenclature are included in most strategic documentation, decision makers are realising they can no longer propose extremely ambitious strategies for their management teams to attempt to execute, hoping that if they even achieve $30 \%$ of the expected result, they will be successful (Malloy, 2016).

Successful strategies of today need to have a balance of the exciting end goals with a sensible and thorough delivery plan, achievable by those on the ground. Keeping this expectation of any strategy top of mind, having a view of the team's (internal \& external) capability gives an added level of confidence, helping leaders work for their stakeholders to achieve the outcomes they expect. Strategies put together with this in mind intrinsically enable teams to work towards improving the customer (and the employee) experience whilst, ensuring the company itself can be competitive in the market and staying ahead of this changing industry.

\section{At the intersection of Strategy and Implementation}

Knowing that a strategy can actually be implemented seems like common sense however, the appeal of exceptional returns, explained by either in house teams or experts, tends to be more believable than not. As such, now where every decision needs to be defendable, there is additional 
pressure to ensure that the correct people and behaviours are in place to deliver. Due to this pressure, firms have to revaluate their approach to strategy creation ensuring they manage their internal operations effectively in addition to delivering exceptional value to their customers. Adding a digital lens to the equation also means, these firms need to account for technologies that may not exist whilst knowing, that any negatively perceived behaviour by anyone, anywhere has the potential to cause a public catastrophe before the boss hears it internally.

It is therefore important to recognise that, plans need to work synergistically to ensure the two aspects (strategy and implementation) work hand in hand (Berman and Dalzell-Payne, 2017). Companies that have been successful in adapting and finding this balance have seen benefits through their journey for reinvention through a new level of agility by their management, flexibility to disruptive environments and finally, recognising that collaborative leadership that can inspire collaboration through these changes.

The role that this digital perspective plays in today's world is that, technology and its ability to benefit the customer is integral for a successful strategy to be created and implemented. Considering the above four stages of strategy development, a digital lens adds the application of analytics, better management of impending disruption and finally, allowing for technology to create transparency and scalability of solutions across the entire company.

As every industry is under pressure to adapt to this digital revolution, the companies that are unable or unwilling to enter the digital age will limit their opportunity for future success. The explosion of analytics has been extremely beneficial to those able to find valuable information and trends in the sea of data. Through finding value in data that the company gathers intrinsically, seeing trends and changing processed based on the outcome of certain decisions or processes, there are a multitude of ways that companies can better themselves through small changes. Looking externally, the benefit seen through monitoring social networks and the different fashions and openly shared feelings of customers adds another layer of feedback for well-defined improvement.

We recognise that even with a digital lens overseeing all strategic planning, what remains consistent is that, the ability to execute needs to be naturally embedded within that strategy. With the adoption of agile project methodology, design thinking and lean continuous improvement, prototyping and revaluating solutions allow for success within a short time period if utilised correctly. Strategists who can learn how to fail fast, adapt and then execute what works in the best possible way rather allow for real evidence to justify decisions as opposed to analysis and hypothesis determining the best course of action (Fuessler et al., 2018).

Regardless of the size of its impact, each strategy should ensure that the capability within the team and the persistence of the leadership clearly exist as, it is all three factors together that will ultimately determine the success (or failure) of any strategy, be it digital or not.

\section{One industry at a time}

In recent years the link between stratagem and implementation have been blurred for successful strategies where, what was once only a top down process directed by executive leadership teams who may be somewhat disconnected from those on the ground has now been flipped. Firms not only face competition from their historic industry rivals but also new firms who may be new to 
the market with a single product or changing industries to try something new. What this new competition shows that, legacy brands and expertise hold less strength if a company is able to deliver a customer solution with a higher level of agility and dependability.

Therefore, to be successful in setting a strategy, firms have to ensure that the steps mentioned above around understanding, deciding and empowering are embedding throughout the entire company. As the industry changes constantly, then so must the strategy whereby, it becomes an iterative process through implementing and reviewing as soon as possible, making small adjustments till the objective is met.

The questions being asked by decision makers has shifted from a business, profit and cost question to that of, how we can disrupt or manage any new disruption; how we can capitalise on the readily available data or; how we can survive if we don't change fast enough. The apprehension felt by every industry can be seen below where industries are seeing changes including:

\subsection{Transportation}

What started as an attempt to create an amazing yet movie like network of taxis, has now become a world renown verb where, the start-up Uber was able to cause an avalanche of disruption to an industry once thought to be an unlikely source of innovation. With competitors from all over the world through Ola in India and BlaBlaCar in Europe personalised transport without owning a car has been changed forever and also opened the door to the customer again being at the centre of the experiential value chain. This has grown further to include all forms of road logistics disrupting long distance transportation of cargo where this accelerated digitisation and thus creation of very sophisticated systems of transportation have completed disrupted the sector (Dierkx et al., 2017).

\subsection{Automotive}

What was once just a necessary tool to get you from point $\mathrm{A}$ to point $\mathrm{B}$, then turning into a symbol of status and identity is now having its entire existence and reason for ownership in question. With consumers having the power of mobility at their fingertips, this industry has seen many consumers are shifting from traditional models of vehicle ownership. Rather than fighting this new trend of ownership models, automotive manufacturers are using new technologies to disrupt the entire creation chain such as working with production staff enabling them with augmented reality-based tooling for them to see their creation before a single piece is cut or; to enable drivers to have access to a range of home-based controls from security and doors to enabling appliances and interior and exterior lights (James et al., 2017). By building new expertise around connectivity, mobility and analytics, reimagining both the customers and employees experience through the entire manufacturing and design supply chain becomes possible.

\subsection{Healthcare}

What was created with a focus on remediation has now shifted to one of prevention. As healthcare is something that affects everyone, the traditional models of having to wait countless hours for 
results or going to various specialists to know what is wrong is being disrupted in the best possible way (Bowser et al., 2017). Recent innovations have been seen by hospitals, companies, governments and start-ups the like all with a focus on the customer (or in this case the patient) experience to achieve affordability, scalability and all with an individually tailored approach. Allowing the customer to manage and take control of their own health with wearables \& IoT solutions enable consistent monitoring during everyday life rather than just sitting still for 15 min at a time.

\section{Conclusion}

Those who are responsible for developing the strategy of a given organisation are in a very different position today when compared with their predecessors. With the addition of new techniques that add value to project management and team collaboration, they have the added benefit of being able to fail fast and learn. That said, there is now an unprecedented level of public scrutiny whereby every decision may need to be defended.

Ultimately, strategy is no longer just a method of diagnosing a problem and submitting factually endorsed recommendations. It is now a creative way to directly lead a company towards continually deploying and scaling innovative ideas in an ever changing, customer centric world with a confidence in technology and the people using it.

\section{References}

Berman, S. \& Dalzell-Payne, P. (2017). Business is being digitally reinvented

Bowser, J., Saxena, S., Fraser, H., \& Marshall, A. (2017). A healthy outlook

Dierkx, K., Marshall, A., \& Peterson, S. (2017). Accidental agitators Digital Reinvention in transportation. Accessed 16th February 2018. url: https://www-935.ibm.com/services/us/gbs/thoughtleadership/drtransportation/

Digital Reinvention in healthcare. Accessed 14th February 2018. url: https://www-935.ibm.com/services/us/gbs/thoughtleadership/drhealthcare/

Fuessler, W., Harmer, M., Lin, S., \& Nordman, C. (2018). Unlocking the potential of digital Digital Reinvention in finance. Accessed 14th February 2018. url: https://www.ibm.com/services/us/gbs/thoughtleadership/drfinance/

Gavetti. G., \& Rivkin, J.W. (2005). How Strategists Really Think: Tapping the Power of Analogy. Accessed 15th February 2018. url: https://hbr.org/search?N=0 $+4294967283 \& N t t=$ origins + of + strategy\&loaded $=1$

Gowers, R. (2016). The last best experience: customer service in a digital world. Internet of Things Blog. Accessed 15th February 2018. url: https://www.ibm.com/blogs/internet-of-things/the-last-best-experience/

IBM Business Analytics. (2013). IBM Social Analytics: The Science behind Social Media Mar- 
keting. Accessed 15th February 2018.

url: http://homepages.stmartin.edu/fac_staff/dconant/MBA623/notes/A-SocialMedia- TheScienceBehindSocialMediaMarketing.PDF

James, D., Lulla, S., Marshall, A., \& Stanley, B. (2017). Driving digital destiny Digital Reinvention in automotive. Accessed 16th February 2018.

url: https://www-935.ibm.com/services/us/gbs/thoughtleadership/drauto/

Malloy, L. (2016). Cognitive services to improve your business strategy. Accessed 14th February 2018.

url: https://www.ibm.com/blogs/watson/2016/07/cognitive-services-improve-business-strategy/

Rishi, S. (2017). How is cloud driving digital disruption across industries? IBM Consulting Blog.

Accessed 16th February 2018.

url: https://www.ibm.com/blogs/insights-on-business/gbs-strategy/cloud-driving-digital-disruptionacross-industries/

Strategy should be too. Institute for Business Value. Accessed 12th February 2018.

url: https://www-935.ibm.com/services/us/gbs/thoughtleadership/strategyconsulting/ 


\section{Biographies}

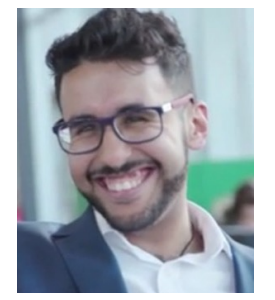

Zuben Rustomjee. Zuben has a background in strategy consultancy for the technology, healthcare and government sectors. He is a Board Member for various not for profit organisations and with the State Government of Victoria. He has held key titles within community organisations all with the focus of leading strategic change and digital transformation. 